\title{
Does Physical Fatigue Affect Color Vision?
}

\section{(ㄷ) (i) (우)}

\author{
Authors \\ Bor Tekavcic ${ }^{1}$, Radoje Čedomir Milić ${ }^{1}$, Manca Tekavcic Pompe ${ }^{2}$
}

\section{Affiliations}

1 University of Ljubljana, Faculty of Sport, Ljubljana, Slovenia

2 Eye Clinic, University Medical Centre, Eye Clinic, Ljubljana, Slovenia

\author{
Key words \\ color discrimination changes, anaerobic metabolic body \\ conditions \\ received 04.12 .2016 \\ revised 19.06.2017 \\ accepted 23.06.2017

\section{Bibliography} \\ DOI https://doi.org/10.1055/s-0043-115378 \\ Sports Medicine International Open 2017; 1: E155-E159 \\ (C) Georg Thieme Verlag KG Stuttgart · New York \\ ISSN 2367-1890

\section{Correspondence} \\ Dr. Manca Tekavcic Pompe \\ Eye Clinic, University Medical Centre, Eye Clinic \\ Grabloviceva 46 \\ 1000, Ljubljana
}

Slovenia

Tel.: + 3861522 1900, Fax: + 38615221960

manca.tekavcic-pompe@guest.arnes.si

\begin{abstract}
The purpose of this study was to establish whether physical fatigue affects color vision. Thirty healthy participants were included in the study ( $M: F=15: 15)$, age $25.3 \pm 4.4$ y, all professional or top amateur athletes. They were exhausted using the Wingate test (WT). Physical fatigue was determined by blood lactate level before the WT and 1, 3, 5, 7 and 10 min after. Color vision was evaluated using the Hardy-Rand-Rittler (HRR) and the Mollon-Reffin Minimalist (MRM) tests before the WT and 5, 10 and 30 min after. Five minutes after the WT 2/30 (6\%) showed affected color vision in the protan axis and 25/30 (83\%) in the tritan axis. Ten and $30 \mathrm{~min}$ after the WT all the participants showed normal color vision in both the deutan and protan axes, whereas $12 / 30(40 \%)$ and $8 / 30$ (26\%), respectively, showed affected color vision in the tritan axis. A gender difference was observed in color vision deficiency and improvement, with female participants being affected more and longer. The study showed that intense physical effort affects color vision with the tritan axis being predominantly affected.
\end{abstract}

\section{Introduction}

Physical fatigue is defined as a temporary physical inability to perform optimally [8]. There are many factors that influence fatigue development, such as intensity and duration of physical effort, individual physical fitness, sleep deprivation, etc. [6]. Apart from the motor system, physical fatigue also influences performance of other systems in the body. Fatigue, as a consequence of intense physical effort, can affect different aspects of visual performance and other visual parameters, such as visuomotor skills [7], contrast sensitivity [10], color vision [20] and intraocular pressure [15].

Physical fatigue can be elicited and its effects can be measured with various tests (one of them can be pedaling or arm cranking at maximal speed against a constant force as in the Wingate test) and in different real-time situations (such as mountaineering, longdistance cycling, etc.).

Color vision is one of the most important components of visual function. In humans it is initiated by the absorption of light by three types of cone photoreceptor in the retina, namely long (L), middle (M) and short (S) wavelength cones [21]. Discrimination of color is described along three color vision axes: protan (red), deutan (green) and tritan (blue). Color vision deficiencies can be congenital or due to acquired conditions, such as altered retinal circulation and neurodegenerative changes in well-known diseases such as glaucoma [14] and diabetic retinopathy [12], where the tritan color vision axis is predominantly affected. Changes in parvocellular visual pathway function, which is responsible for processing colored visual information, during physical effort has mainly been described in mountaineering and at high altitude and has been detected both psychophysically $[5,11,20]$ and electrophysiologically with altered S cone function [15].

Psychophysical and electrophysiological studies have demonstrated that the $S$ cone function is affected to a greater extent than $\mathrm{M}$ and $\mathrm{L}$ cone functions and, therefore, the tritan color vision axis is affected more often compared to protan and deutan color vision 
axes in altered metabolic body conditions due to the physical effort at high altitude. However, it has been shown that alterations in color vision due to changed metabolic body conditions are transient and return to normal when the physical effort at high altitude is stopped and subjects return to the initial altitude [20]. Therefore, a transient blue-yellow color vision deficiency $[5,11,20]$ or transient $S$ cone dysfunction [15] is described in these studies.

Perfect color vision is also of major importance in various competitive sports, such as cross-country skiing, where on-time visual recognition of signposts and other visual stimuli can contribute to a better final result. The effect of intense exercise on the eyes and brain has not been well studied yet. Color vision testing is one of the possibilities to test visual performance and visual pathway function.

To our knowledge, there has been no study investigating color vision changes due to extreme fatigue after exercising to the level of anaerobic body conditions. Therefore, the aim of this study was to establish whether physical fatigue affects color vision. Our research hypothesis was that color perception is altered after a highimpact physical activity.

\section{Methods}

Thirty healthy participants in excellent physical shape with normal color vision were included in the study, 15 men and 15 women, aged $25.3 \pm 4.4$ years, all professional or top amateur athletes, most of them practicing in winter sports (such as cross-country skiing and biathlon). The study was ethically approved and followed the tenets of the Declaration of Helsinki and it meets the ethical standards of the journal [9].

All of the participants performed the Wingate test (WT). The WT test was conducted on a calibrated friction-loaded cycle ergometer (Monark 894E Peak bike, MONARK, Varberg, Sweden) interfaced with a microcomputer. The ergometer was equipped with toe clips to prevent the subjects' feet from slipping. The test consisted of a 30 s maximal sprint against a constant braking resistance dependent on the subjects' body mass $\left(0.075 \mathrm{~kg} . \mathrm{kg}^{-1}\right.$ body mass) according to the optimization tables of Bar-Or [2]. The test began from a rolling start, at maximal individual cadence against minimal resistance. When the maximum pedal rate was achieved, a countdown of "3-2-1-go!" was given before dropping the weight basket with the load. Prior to the test, the participants were instructed to pedal as fast as they could for $30 \mathrm{~s}$.

To assess the body metabolic status, blood lactate was measured (EBIO plus, Eppendorf, Germany) before the WT and 1, 3, 5, 7 and 10 min after it in all participants. Blood samples were taken from the earlobe.

All the participants had normal color vision according to the standard Ishihara clinical test and normal or corrected-to-normal visual acuity with no recorded pathology or ocular abnormalities.

Color vision was evaluated using the Hardy-Rand-Rittler (HRR) and Mollon-Reffin Minimalist (MRM) tests before the WT and 5, 10 and $30 \mathrm{~min}$ after the test. Both tests were performed under standardized lighting conditions (Daylight Illuminator, Richmond Products, Albuquerque, NM, USA).
The Hardy-Rand-Ritter test (4th edition, Richmond Products) is a widely used clinical test that consists of pseudoisochromatic plates with which all three color vision axes can be evaluated [3].

The Mollon-Reffin Minimalist test [13] has shown its value because it is quick to administer and presents the easiest possible task to the participant, who is requested simply to identify a colored probe chip among five achromatic distractor chips of varying lightness. The probe chips vary in chroma, and their chromaticities lie along dichromatic confusion lines (protan, deutan and tritan) that pass through the chromaticity of the achromatic chips. As in the first Ishihara plate, the first chip used is a saturated orange, which does not lie on any confusion line, to demonstrate the task and identify pretense or gross pathology. A simple staircase procedure is then used to establish, for each confusion line, the number of the chip that can be reliably distinguished from the distractors. Altogether there are 15 chips, 5 from each confusion line (deutan, protan and tritan). The investigator marks down a number for the last chip distinguished from distractors ( 1 , normal; 2 , minimally reduced; 3 , moderately reduced; 4 , markedly reduced; 5 , extremely reduced color vision in a particular axis: P-protan, D-deutan, T-tri$\tan )$. The test has proved its value in testing children [18] as well as testing color vision in extreme environmental conditions such as high altitude [20].

The percentage of participants with abnormal color vision in the protan, deutan and tritan color vision axes was studied 5, 10 and 30 min after the WT. Gender difference was also evaluated.

The results were statistically evaluated with one-way ANOVA (lactate levels) and non-parametric Wilcoxon paired-sample signed-rank test (color vision test). The significance values were adjusted for multiple comparisons with Bonferroni's correction. Statistical significance was set at $p<0.05$, whereas Spearman $r^{2}$ was used for correlation. Average values \pm SD, as well as $95 \% \mathrm{Cl}$ and Cohen's d effect size were reported.

\section{Results}

The blood lactate levels before the WT and 1, 3, 5, 7 and 10 min after are shown in > Fig. 1, both for the entire group (all) and separately for female and male participants. The average lactate level for the entire group of participants before the WT was $1.3 \pm 0.3$, it increased after $1 \mathrm{~min}$ to $3.4 \pm 1.0(p<0.001,95 \% \mathrm{Cl} 2.9-3.7, d=3.2)$, and remained elevated after $3 \mathrm{~min} 8.8 \pm 1.4(\mathrm{p}<0.001,95 \% \mathrm{Cl} 8.2-$ $9.3, d=4.5)$, after $5 \min 9.7 \pm 1.4(95 \% \mathrm{Cl} 9.1-10.2, d=0.64)$, after $7 \mathrm{~min} 9.9 \pm 1.4(95 \% \mathrm{Cl} 9.3-10.3, \mathrm{~d}=0.14)$ and after $10 \mathrm{~min} 9.5 \pm 1.5$ (95\% Cl 8.9-10.0, d=0.27) mmol/l ( Fig. 1).

Color vision evaluated with both the HRR and the MRM tests before the WT showed normal color vision in all 3 axes in all 30 participants.

Color vision evaluated with the HRR test 5 min after the WT showed tritan axis defects in 5/30 (17\%) participants, 1 male and 4 females, whereas at 10 and 30 min post-WT all participants showed normal color vision. All 5 participants showed a medium level blue-yellow defect according to the HRR scoring system with errors in plate number 17 and/or 18.

Color vision evaluated with the MRM test 5 min after the WT showed protan axis defects in $2 / 30(6 \%, \mathrm{p}>0.05)$ participants and 


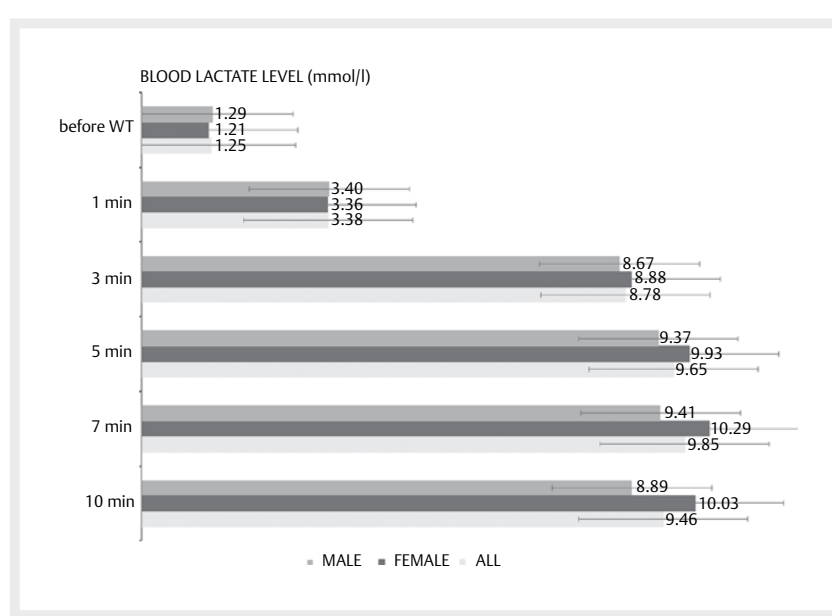

- Fig. 1 The blood lactate level before the Wingate test and 1, 3, 5, 7 and $10 \mathrm{~min}$ after. Results for the entire group (ALL) and separately for female and male participants shown in a chart.

tritan axis defects in 25/30 (83\%, $\mathrm{p}<0.001, \mathrm{~d}=3.3$ ) participants; however, all the participants showed normal color vision in the deu$\tan$ axis.

Ten and 30 min after the WT all the participants showed normal color vision in deutan and protan axes, whereas color vision in the tritan axis remained affected in $12 / 30(40 \%, p=0.001, d=1) 10 \mathrm{~min}$ after the WT and in 8/30 (26\%, p = 0.02, $d=0.2) 30$ min after the WT.

There was no significant correlation between the blood lactate level and changes in the tritan axis discrimination for the entire group of participants $\left(r^{2}=0.001, p=0.85\right)$.

Tritan color vision defects for the entire group of participants as well as separately for female and male participants are shown in - Fig. 2. Most of the participants showed transient changes in color perception in the tritan axis, however the changes were more profound and lasted longer in the female participants.

\section{Discussion}

The results of this study demonstrate that color vision can be affected after short-duration high-impact physical activity that induces body acidosis. Transient blue (tritan) color deficiency was observed in more than $80 \%$ of the participants 5 min after the provocational Wingate test was performed, whereas green (deutan) and red (protan) color vision axes were only slightly affected.

Gender differences were also observed. The tritan axis was affected to a greater extent in female compared to male participants. Namely, $34 \%$ of all female participants showed a moderately affected tritan color vision axis five minutes after the WT, whereas only $7 \%$ of the male participants showed a similar tritan color vision deficiency. The improvement rate was also different between the genders. After 30 min the tritan color vision axis remained minimally affected in $33 \%$ (5) of female and in $20 \%$ (3) of male participants. To our knowledge there has been no similar gender difference report on color vision after high-impact physical activity. However, it is known that body metabolism during sports activities differs between genders, the difference being greater after short

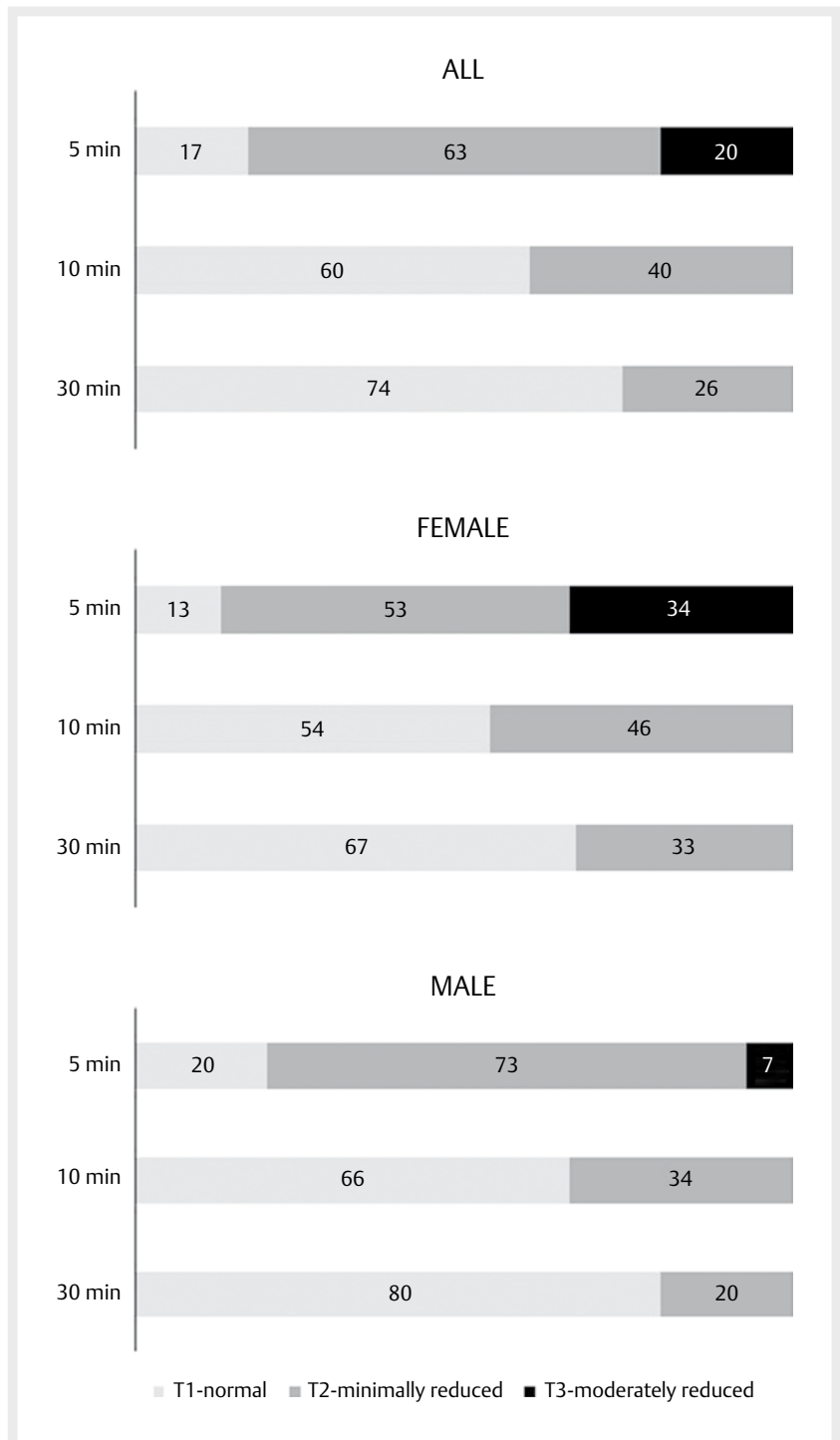

- Fig. 2 Tritan color vision defects for the entire group (ALL) and separately for female and male participants shown in percentages. $\mathrm{T} 1$ - normal color vision in the tritan axis. T2 - minimally reduced color vision in the tritan axis. T3 - moderately reduced color vision in the tritan axis.

and high-volume physical activity and lesser after prolonged strenuous activity such as running a marathon [16]. In this study, the blood lactate level differed between genders at 5, 7 and 10 min post-WT, with female participants showing lower values at all measurements, which was also previously described [16].

Physical fatigue in this study was provoked by using a short-duration, high-intensity Wingate test. However, the results of color vision deficiency might be different if prolonged strenuous physical activity were utilized. In the study of color vision at high altitude with prolonged strenuous mountaineering activity, the tritan color vision axis was also predominantly affected and color vision normalized in all participants after returning to sea level [20]. However, there were no female participants included in the high-altitude study to compare the gender differences. 
All the participants in the present study were young professional or top amateur athletes, who were highly motivated and used to extremely strenuous physical exercise. It would also be interesting to study the general population to find out whether color vision changes can be observed after higher impact physical activity. The age of the participants probably also played a role in this study. Age-related changes of color vision in the tritan axis have been previously described, also using the MRM test [13]. The reduced color discrimination ability in this study may also be influenced by other reasons, such as attention disturbance due to extreme fatigue after strenuous exercise. This influence would probably be the strongest at 5 min rather than at 10 min after the WT.

The reason why the tritan color vision axis is affected to a greater extent compared to protan and deutan axes may lie in a greater susceptibility of S cones to different metabolic conditions in the retinal circulation. Retinal and especially $S$-cone ischemia or transient hypoperfusion may also play a role in color vision deficiency described in this study. It is well known that $S$ cones differ both morphologically [1] and metabolically [22] from $\mathrm{M}$ and $\mathrm{L}$ cones. Besides, the distribution of $S$ cones in the human retina is different compared to $\mathrm{L}$ and $\mathrm{M}$ cones. In contrast to $\mathrm{L}$ and $\mathrm{M}$ cones, $\mathrm{S}$ cones are sparse in the peak-cone density center and relatively more densely populated in the periphery of the retina [4]. This might be the reason why hypoxic-ischemic conditions, to which retinal periphery is far more susceptible than the central retina, predominantly affect the tritan color vision axis. However, it has previously been well described that the tritan color vision axis is predominantly affected in experimental hypoxic conditions [19].

Because $S$ cones represent only about $5 \%$ of all human cones [22], their function is difficult to test. This might also be the reason why tritan color vision deficiency is not detected more frequently in different diseases and altered metabolic conditions of the human body. However, diabetic patients without clinically significant diabetic retinopathy show color vision changes predominantly in the tritan color vision axis [12].

The present study did not show a correlation between the blood lactate level and color vision deficiency at 5 min after the WT. From the $3^{\text {rd }}$ minute after the WT, the blood lactate level had already reached a plateau and showed only minor changes. The correlation might have been present if color vision had also been tested 2 min after the WT, but this was technically impossible due to extreme fatigue most participants exhibited. On the other hand, in the highaltitude study changes in the tritan axis correlated well with increased heart rate and decreased oxygen saturation [20]. It is possible that these correlations would also be manifested in the present study.

The limitations of the present study include the relatively small number of participants, age limitation (young athletes) and fitness level (all the participants were in excellent physical shape). It would be interesting to broaden the study to a larger number of participants, including different age groups and participants at different fitness levels. The color vision tests used in the present study were technically easiest to perform after high-impact physical exercise, however the results obtained with an anomaloscope would probably be more accurate as far as the stage of tritan color vision deficiency is concerned.
According to the present study, we conclude that short-duration, high-impact physical exercise can affect color vision in young, healthy athletes, which also confirms our research hypothesis. The tritan (blue-yellow) color vision axis was predominantly affected. A gender difference was also observed, in that tritan color vision was affected to a greater extent and improvement was slower in female compared to male participants.

\section{Acknowledgements}

The authors would like to thank Professor John Mollon, who provided the color vision test and gave us useful instructions, and all the participants in the study. We would also like to thank Mrs Nada Štrucelj for her technical support, Dr Maja Sustar for helping us with the statistics and Professor Veronica Kralj I glič for her valuable comments. This study was supported by the Faculty of Sport research grant. Authors have no financial interest.

\section{Conflict of Interest}

The authors declare that they have no conflict of interest.

\section{References}

[1] Ahnelt PK, Kolb H, Pflug R. Identification of a subtype of cone photoreceptor, likely to be blue sensitive, in the human retina. J Comp Neurol 1987; 255: 18-34

[2] Bar-Or O. The Wingate anaerobic test. An update on methodology, reliability and validity. Sports Med 1987; 4: 381-394

[3] Cole BL, Lian KY, Lakkis C. The new Richmond HRR pseudoisochromatic test for colour vision is better than the Ishihara test. Clin Exp Optom 2006; 89: 73-80

[4] Curcio CA, Allen KA, Sloan KR, Lerea CL, Hurley JB, Klock IB, Miliam AH. Distribution and morphology of human cone photoreceptors stained with anti-blue opsin. J Comp Neurol 1991; 312: 610-624

[5] Davies AJ, Morris DS, Kalson NS, Wright AD, Imray CH, Hogg CR. Birmingham Medical Research Expeditionary Society. Changes to colour vision on exposure to high altitude. J R Army Med Corps 2011; 157: 107-109

[6] Gandevia SC. Spinal and supraspinal factors in human muscle fatigue. Physiol Rev 2001; 81: 1725-1789

[7] Gao Y, Chen L, Yang SN, Wang H, Yao J, Dai Q, Chang S. Contributions of visuo-oculomotor abilities to interceptive skills in sports. Optom Vis Sci 2015; 92: 679-689

[8] Hawley JA, Reilly T. Fatigue revisited. J Sports Sci 1997; 15: 245-246

[9] Harriss D], Atkinson G. Ethical standards in sports and exercise science research: 2016 update. Int J Sports Med 2015; 36: 1121-1124

[10] Jafarzadehpur E, Mirzajani A, Hatami M, Musavian R, Abbasi E. Comparison of blue-yellow opponent color contrast sensitivity function between female badminton players and non-athletes. Asian 」 Sports Med 2013; 4: 107-113

[11] Karakucuk S, Oner AO, Goktas S, Siki E, Kose O. Color vision changes in young subjects acutely exposed to $3,000 \mathrm{~m}$ altitude. Aviat Space Environ Med 2004; 75: 364-346

[12] Lakowski R, Aspinell PA, Kinnear PR. Association between colour vision losses and diabetes mellitus. Ophthalmic Res 1972; 4: 145-159 
[13] Mollon JD, Astell S, Reffin JP. A minimalist test of colour vision. In: Drum XB, Moreland JD, Serra A. (eds) Colour Vision Deficiencies. Dordrecht: Kluwer; 1991: 59-67

[14] Niwa Y, Muraki S, Naito F, Minamikawa T, Ohji M. Evaluation of acquired color vision deficincy in glaucoma using the Rabin cone contrast. Invest Ophthalmol Vis Sci 2014; 10: 6686-6690

[15] Qureshi Al. Effects of exercise on intraocular pressure in physically fit subjects. Clin Exp Pharmacol Physiol 1996; 23: 648-652

[16] Ruby BC, Robergs RS. Gender differences in substrate utilisation during exercise. Sports Med 1994; 17: 393-410

[17] Schatz A, Dominik Fischer M, Schommer K, Zrenner E, Bartz-Schmidt $\mathrm{KU}$, Gakeler F, Willmann G. Attenuation of S-cone function at high altitude assessed by electroretinography. Vis Res 2014; 97: 59-64
[18] Shute R, Leat SJ, Woodhouse JM. (eds) Assessing Children's Vision: A handbook. Oxford, UK: Butterworth-Heinemann; 1998

[19] Smith VC, Ernest JT, Pokorny J. Effect of hypoxia on FM 100-Hue test performance. Mod Probl Ophthalmol 1976; 17: 248-256

[20] Tekavcic-Pompe M, Tekavcic I. Color vision in the tritan axis is predominantly affected at high altitude. High Alt Med Biol 2008; 9: $38-42$

[21] Wald G, Brown PK. Human color vision and color blindness. Cold Spring Harb Symp Quant Biol 1965; 30: 345-361

[22] Yamamoto S, Kamiyama M, Nitta K, Yamada T, Hayasaka S. Selective reduction of the $\mathrm{S}$ cone electroretinogram in diabetes. $\mathrm{Br}$ J Ophthalmol 1996; 80: 973-975 